\title{
Mycophenolate Mofetil Alone and in Combination with Tacrolimus Inhibits the Proliferation of HT-29 Human Colonic Adenocarcinoma Cell Line and Might Interfere with Colonic Tumorigenesis
}

\author{
GALINA LING ${ }^{1,2,3}$, SERGIO LAMPRECHT ${ }^{4,5}$, GEORGE SHUBINSKY ${ }^{3,6}$, LIDIA OSYNTSOV ${ }^{3,7}$, \\ BARUCH YERUSHALMI ${ }^{1,2,3}$, ILYA PINSK $^{3,8}$, VERED PINSK $^{3,9}$ and EDUARD LING EN $^{3,10}$ \\ ${ }^{1}$ Pediatric Ambulatory Service, ${ }^{2}$ Pediatric Gastroenterology and Nutrition Unit, and \\ ${ }^{10}$ Pediatrics Department B, Saban Pediatric Medical Center for Israel, Beer Sheva, Israel; \\ ${ }^{3}$ Faculty of Health Sciences, Ben-Gurion University of the Negev, Beer Sheva, Israel; \\ ${ }^{4}$ Institute of Gastroenterology and Hepatology, ${ }^{6}$ Flow Cytometry Unit, Hematology Laboratory, \\ ${ }^{7}$ Institute for Pathology, ${ }^{8}$ Surgery Department B and Colorectal Surgery Unit, \\ Soroka University Medical Center, Beer Sheva, Israel; \\ ${ }^{5}$ Department of Clinical Biochemistry and Pharmacology, Faculty of Health Sciences, \\ Ben-Gurion University of the Negev, Beer Sheva, Israel; \\ ${ }^{9}$ Pediatric Gastroenterology Unit, Assuta Ashdod University Hospital, Ashdod, Israel
}

\begin{abstract}
Background/Aim: Familial adenomatous polyposis (FAP) was found to be completely reversed in a patient treated with mycophenolate mofetil (MMF) and tacrolimus following kidney transplantation. In this preliminary study, we assessed whether MMF and tacrolimus alone or in combination interfere with the cell cycle and proliferation in a human colonic adenocarcinoma cell line and in the colonic polyps of the patient with FAP. Materials and Methods: Human colonic adenocarcinoma HT-29 cells were treated with tacrolimus and MMF alone and in combination at different concentrations. Cell viability and proliferation were assessed using the MTT assay. Cell-cycle distribution was analyzed by flow cytometry. Expression of Ki-67, a marker of mitotic activity, was evaluated in the patient's colonic polyps before and under drug treatment. Results: MMF in combination with tacrolimus induced S-phase cell-cycle arrest and markedly inhibited HT-29 cell proliferation. Ki-67 expression in the patient's colonic polyps was significantly reduced following combined tacrolimus and MMF treatment. Conclusion: MMF and
\end{abstract}

Correspondence to: Dr. Eduard Ling, MD, Ph.D., Pediatrics Department B, Saban Pediatric Medical Center for Israel, Soroka University Medical Center, Rager Avenue, Beer Sheva, Israel. Tel: +972 86400755, Fax: +972 86287163; e-mail: ling@bgu.ac.il

Key Words: MMF, tacrolimus, synergism, antiproliferative effect, HT-29 cells. tacrolimus synergistically inhibited proliferation of a human colonic adenocarcinoma cell line and interfered with the expansion of colonic crypt proliferation in the polyp from a patient with FAP. The results confirm our clinical observation and indicate the possibility of novel approach to therapy of colorectal neoplasia.

Immunosuppressive therapy, which is used to prevent rejection of organ transplants and for treatment of autoimmune diseases, is known to increase the risk of malignancies and infections and, therefore, should be used cautiously or avoided in patients with cancer or pre-neoplastic lesions. As a matter of fact, neoplasia is a significant factor contributing to morbidity and mortality of renal allograft recipients, with up to $18 \%$ of post-transplantation death cases being attributed to malignancy. Frequent cases of cancerrelated death in such patients were lymphoma, followed by lung and kidney cancer (1). Of note, risk of colon cancer is also elevated in patients post-transplantation (2).

It should be noted, however, that the choice of specific post transplantation therapy might differentially influence the risk of development of colorectal neoplasia. Recently, Safaeian et al. analyzed the risk of colorectal cancer in US patients post-solid organ transplantation and did not observe elevated incidence of colorectal cancer in those treated with tacrolimus and mycophenolate mofetil (MMF), as opposed to those treated with cyclosporine A and azathioprine posttransplantation (3). Consonant with these findings, we 
recently described a case of complete regression of colonic polyps in a teenager with familial adenomatous polyposis (FAP) who was treated with tacrolimus and MMF following kidney transplantation (4).

These observations prompted us to examine whether tacrolimus and MMF treatment impedes proliferation of a human colonic adenocarcinoma cell line and FAP colonic polyps.

\section{Materials and Methods}

Cell line. The human colonic adenocarcinoma cell line HT-29 (ATCC HTB-38; ATCC, Manassas, VA, USA), known to harbor nonsense adenomatous polyposis coli (APC) gene mutation (5), was grown in DMEM supplemented with $10 \%$ fetal calf serum, 2 mM Lglutamine and 100 units $/ \mathrm{ml}$ penicillin, $100 \mu \mathrm{g} / \mathrm{ml}$ streptomycin, and 12.5 units $/ \mathrm{ml}$ nystatine at $37^{\circ} \mathrm{C}$ in a humidified chamber with $95 \%$ air $/ 5 \% \mathrm{CO}_{2}(6)$. These cells are undifferentiated when grown in these conditions (6). Cell culture media and supplements were purchased from Biological Industries, Beit HaEmek, Israel.

For experimental purposes, cells were treated with tacrolimus $(0.1 \mu \mathrm{M}$ and $1 \mu \mathrm{M}), \mathrm{MMF}(1$ or $10 \mu \mathrm{g} / \mathrm{ml})$ or a combination of tacrolimus and MMF $(0.1 \mu \mathrm{M}$ and $1 \mu \mathrm{g} / \mathrm{ml}, 0.1 \mu \mathrm{M}$ and $10 \mu \mathrm{g} / \mathrm{ml}$, $1 \mu \mathrm{M}$ and $1 \mu \mathrm{g} / \mathrm{ml}$, and $1 \mu \mathrm{M}$ and $10 \mu \mathrm{g} / \mathrm{ml}$, respectively) as described elsewhere $(7,8)$. Control cells were treated with vehicle alone. It should be noted that MMF is a prodrug that is rapidly hydrolyzed into its active form, mycophenolic acid (MPA), by serum esterases in vivo, or by esterases in serum or plasmacontaining cell culture media, or by tissue esterases (9-11). MMF and tacrolimus were purchased from Sigma-Aldrich Israel, Ltd, Rehovot, Israel.

Ki-67 staining. Specimens of tubular adenoma with low-grade dysplasia obtained from FAP patient prior to initiation of tacrolimus and MMF treatment and tubular adenoma specimens obtained after 6 months of tacrolimus and MMF treatment were analyzed. Formaline-fixed paraffin-embedded $5 \mu \mathrm{m}$-thick tissue sections were deparaffinized, rehydrated and stained for Ki-67 using a monoclonal antibody to human Ki-67 (MIB1) (Dako, Agilent, Santa Clara, CA, USA). Immunostaining was performed using an automated platform (BenchMark XT, Ventana Medical Systems Inc., Tucson, AZ, USA) according to the manufacturer's instructions. The staining was evaluated by counting positively stained colonocytes in 20 randomized fields per slide. Scoring was expressed as the average count of Ki-67-positive cells per 100 colonocytes counted.

Viability and proliferation assay. Aliquots of $5 \times 10^{3}$ cells per well were seeded into the 96 -well plates and incubated with tacrolimus, MMF or combination of tacrolimus and MMF at concentrations indicated above. Cells were grown for 24, 48, 72 and 96 hours. At the end of each time period the cell viability was assessed using the MTT assay (CellTiter $96{ }^{\circledR}$ Assay; Promega Corp, Madison, WI, USA) according to the manufacturer's instructions. Briefly, $15 \mu$ of the Dye Solution was added to each well and the plate was incubated at $37^{\circ} \mathrm{C}$ for 4 hours in a humidified, atmosphere with $5 \% \mathrm{CO}_{2}$. Afterwards, $100 \mu \mathrm{l}$ of the Solubilization Solution/Stop Mix were added to each well. Following additional incubation of 1 hour, the contents of each well were gently pipetted in order to obtain a uniformly colored solution and absorbance was read at $570 \mathrm{~nm}$ wavelength using a 96- well plate reader. The results are expressed as a percentage of the respective control absorbance at each time point.

Cell-cycle analysis. Cell-cycle analysis was performed by flow cytometry using Propidium Iodide Flow Cytometry Kit (Abcam, Cambridge, UK). Briefly, aliquots of $2 \times 10^{5}$ cells per well were seeded into 6-well plates and incubated with tacrolimus, MMF, or combination of tacrolimus and MMF. Cells were grown for 48 and 96 hours. At the end of each respective time period, cells were harvested, washed twice with phosphate buffered saline, $\mathrm{pH} 7.4$, fixed with $70 \%$ ice-cold ethanol, treated with RNase A, stained with $50 \mu \mathrm{g} / \mathrm{ml}$ of propidium iodide for 20 minutes, according to the manufacturer's instructions. Data acquisition was performed by FACSCanto II flow cytometer (BD Biosciences, San Jose, CA, USA). Ten thousand cells per sample were collected, and propidium iodide staining intensity was plotted on a linear scale using BD FACSDiva Software version 6.1.3 (BD Biosciences). Cell-cycle profiles were analyzed using Weasel v3.4.2 software (WEHI, Parkville, Victoria, Australia).

Statistical analysis. Cell proliferation experiments were performed in triplicates and repeated three times. Cell-cycle experiments were performed in quadruplicates and repeated twice. Statistical significance was evaluated using two-tailed Student's $t$-test. Differences were considered statistically significant with $p<0.05$. Results are presented as the mean \pm standard deviation.

\section{Results}

Expression of Ki-67 antigen. Expression of Ki-67 antigen, a known proliferative marker (12), was assessed in low-grade tubular adenoma specimens obtained pre-kidney transplantation from a patient with FAP, i.e. prior to initiation of tacrolimus and MMF treatment, and in low-grade tubular adenoma specimens that were obtained 6 months after kidney transplantation (4), and expressed as the percentage of Ki-67-positive colonocytes. The Ki-67 score prior to initiation of tacrolimus and MMF treatment (Figure 1A) was $35.5 \pm 5.0 \%$ (range $=31-44 \%$ ), whereas 6 months post-kidney transplantation under tacrolimus and MMF treatment, the score significantly decreased to $16.6 \pm 6.6 \%$ (range $=7-30 \%$ ), $p<0.001$ (Figure 1B). The results indicate decreased expression of Ki-67 antigen in FAP polyps following drug treatment, suggesting decreased cell proliferative activity and impaired expansion of the crypt proliferative compartment in FAP colonic adenomas, a hallmark of hereditary and sporadic colonic cancer.

Proliferation assay. Significant inhibition of proliferation of HT-29 cells was observed following 72 and 96 hours of treatment with $10 \mu \mathrm{g} / \mathrm{ml}$ MMF alone $(p<0.002$ compared to combination with $1 \mu \mathrm{M}$ tacrolimus $(56.9 \pm 20.9 \%$, $76.4 \pm 24.4 \%$, respectively, $p<0.001$ compared to respective control; Figure 2A). Treatment of HT-29 cells with a combination of $10 \mu \mathrm{g} / \mathrm{ml} \mathrm{MMF}$ and $0.1 \mu \mathrm{M}$ tacrolimus resulted in marked inhibition of proliferation of HT-29 cells 

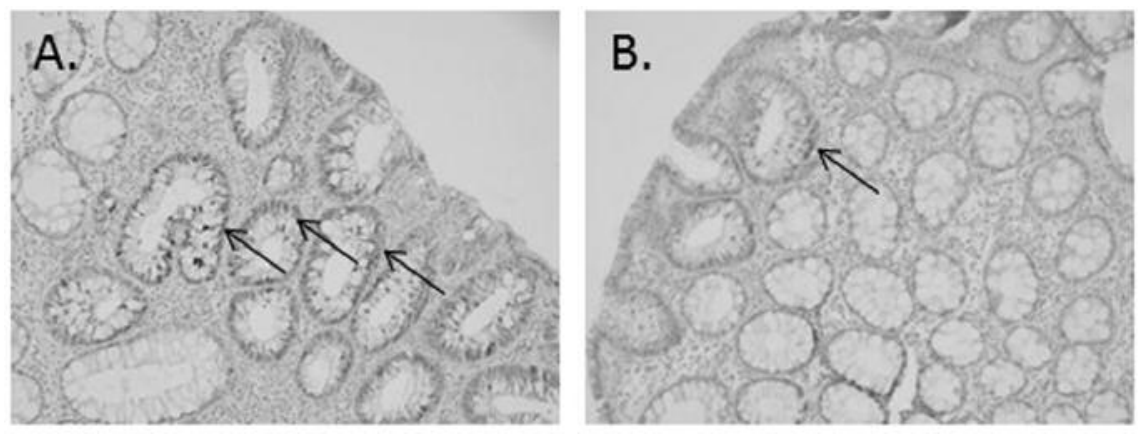

Figure 1. Immunostaining for Ki-67 in colonic tubular adenoma samples obtained before initiation of tacrolimus and mycophenolate mofetil (MMF) treatment $(A)$ and 6 months after commencement of treatment (B). Selected positively stained nuclei are indicated with black arrows. Marked decrease in Ki-67 expression following combined treatment can be seen. Representative slides are presented (original magnification $\times 100$ ).

at $24,48,72$ and 96 hours $(82.5 \pm 11.7 \%, 58.5 \pm 11.3 \%$, $49.8 \pm 29.4 \%, 54.8 \pm 8.7 \%$, respectively, $p<0.005$ compared to respective control). It should be noted that the combination of $10 \mu \mathrm{g} / \mathrm{ml} \mathrm{MMF}$ and $0.1 \mu \mathrm{M}$ tacrolimus inhibited the proliferation of HT-29 cells significantly more effectively than treatment with $10 \mu \mathrm{g} / \mathrm{ml} \mathrm{MMF}$ alone $(p<0.01$ at all respective time points; Figure 2A).

Treatment of cells with combination of $1 \mu \mathrm{g} / \mathrm{ml} \mathrm{MMF}$ and $0.1 \mu \mathrm{M}$ tacrolimus also resulted in significant inhibition of growth of HT-29 cells at 72 and $96 \mathrm{~h}(48.4 \pm 8.1 \%$, $86.1 \pm 25.45 \%, p<0.02$, compared to respective control or to treatment with $1 \mu \mathrm{g} / \mathrm{ml}$ MMF alone). Likewise, combination of $1 \mu \mathrm{g} / \mathrm{ml} \mathrm{MMF}$ and $1 \mu \mathrm{M}$ tacrolimus impeded proliferation of HT-29 cells at 72 and $96 \mathrm{~h}(73.39 \pm 10.38 \%, 89.2 \pm 21.05$, $p<0.05$ compared to respective control; $p<0.02$ compared to treatment with $1 \mu \mathrm{g} / \mathrm{ml} \mathrm{MMF}$ alone at $96 \mathrm{~h}$ ). Transient inhibition of proliferation at $72 \mathrm{~h}$ was observed following treatment with $1 \mu \mathrm{g} / \mathrm{ml}$ MMF $(71.6 \pm 35.7 \%, p<0.002$ compared to respective control; Figure 2B).

Tacrolimus alone at both concentrations used did not influence the growth of HT-29 cells (Figure 2C), the distinct trend for acceleration of cell proliferation under influence of $1 \mu \mathrm{M}$ tacrolimus was not statistically significant.

Cell-cycle analysis. To understand whether the inhibitory effect of MMF and tacrolimus on the growth of HT-29 cells results from cell mitotic arrest, we analyzed the effect of these drugs on cell-cycle transition using propidium iodide staining and flow cytometric analysis.

Flow cytometric analysis of cell-cycle distribution of control cells demonstrated $49.7 \pm 7 \%$ of cells in $\mathrm{G}_{1}$ phase, $32.6 \pm 3.6 \%$ cells in $S$ phase, and $18.1 \pm 4.9 \%$ cells in $\mathrm{G}_{2} / \mathrm{M}$ phase. The accumulation of HT-29 cells in the S-phase of the cell cycle was detected following $48-\mathrm{h}$ exposure to $10 \mu \mathrm{g} / \mathrm{ml} \mathrm{MMF}$ (50.8 $\pm 22.3 \%, p<0.04$ compared to control), $1 \mu \mathrm{M}$ tacrolimus with $10 \mu \mathrm{g} / \mathrm{ml}$ MMF $(60.5 \pm 17.5 \%, p<0.001$, compared to control), $1 \mu \mathrm{M}$ tacrolimus with $1 \mu \mathrm{g} / \mathrm{ml} \mathrm{MMF} \mathrm{(38.4 \pm 5.2 \% ,}$ $p<0.03$, compared to control), $0.1 \mu \mathrm{M}$ tacrolimus with $10 \mu \mathrm{g} / \mathrm{ml}$ MMF $(52.6 \pm 10.6 \%, p<0.001$, compared to control), and $0.1 \mu \mathrm{M}$ tacrolimus with $1 \mu \mathrm{g} / \mathrm{ml} \mathrm{MMF}(59.0 \pm 20.6 \%$, $p<0.001$, compared to control; Figure 3 ). Tacrolimus alone and $1 \mu \mathrm{g} / \mathrm{ml} \mathrm{MMF}$ failed to induce cell-cycle mitotic arrest.

Cell-cycle alterations were not observed following $96 \mathrm{~h}$ of treatment (data not shown).

\section{Discussion}

The salient finding of this report is the significant decrease in the number of proliferating epithelial cells and in the expansion of the proliferative crypt compartment in the colonic crypts of colonic adenomas of a patient with FAP who underwent treatment with $\mathrm{MMF}$ and tacrolimus compared to control untreated FAP colonic adenomas. We believe that the present ex vivo finding, albeit preliminary, in conjunction with histological observations of colonic polyps biopsies from the same FAP patient showing the absence of dysplasia and typical adenomatous changes after 6 months of the drug treatment (4), strengthens the view that combined MMF and tacrolimus treatment impedes the development of colonic cancer. On the basis of these observations, the question arises: What are the molecular mechanisms underpinning the anticancer effect of these immunosuppressive drugs?

In vivo the morpholino ethyl prodrug MMF is completely converted to the active moiety, MPA, by the action of esterases present in serum and in tissues, including the gastrointestinal tissues (9-11). MPA is a potent, selective, uncompetitive, and reversible inhibitor of inosine monophosphate dehydrogenase (IMPDH), a key enzyme in the synthesis of purine nucleotides and, therefore, essential for building nucleotide pools. MPA is very effective in blunting $\mathrm{T}$ - and B-lymphocyte proliferation and, thereby, is 
A

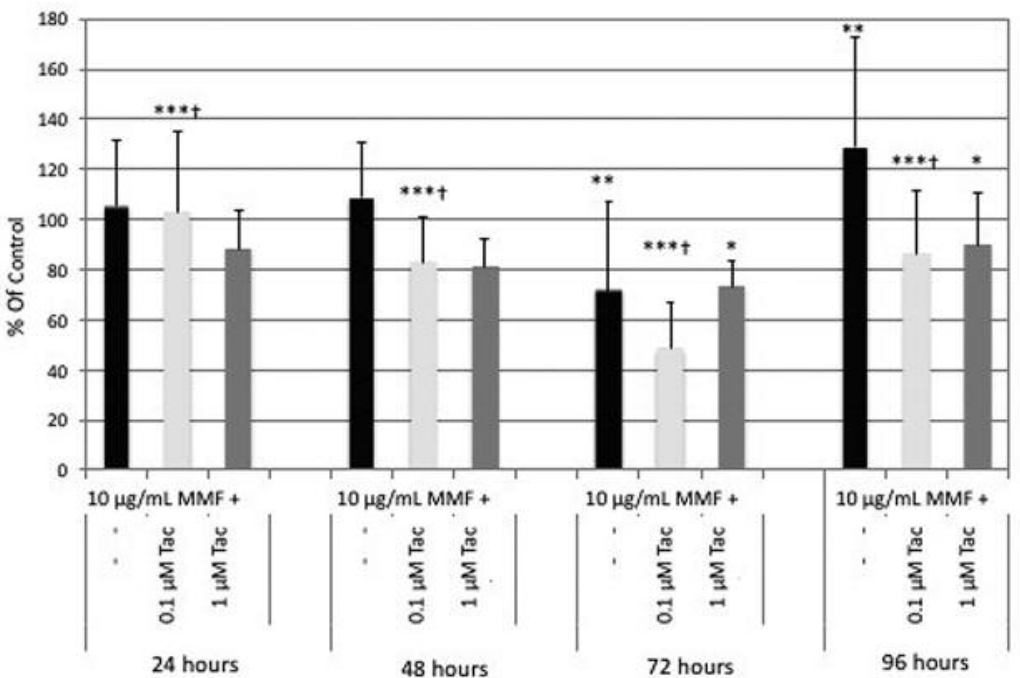

B

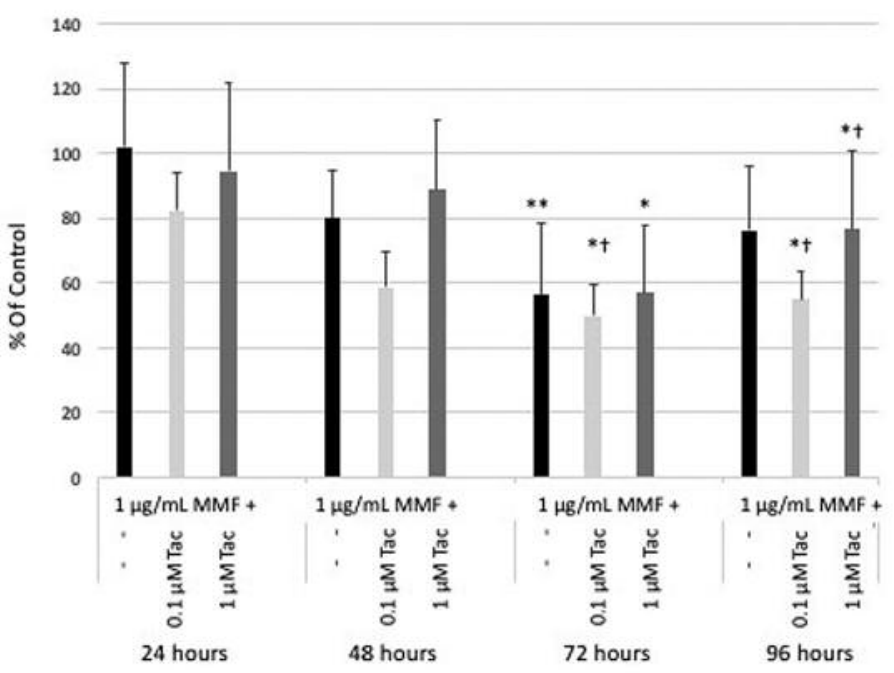

C

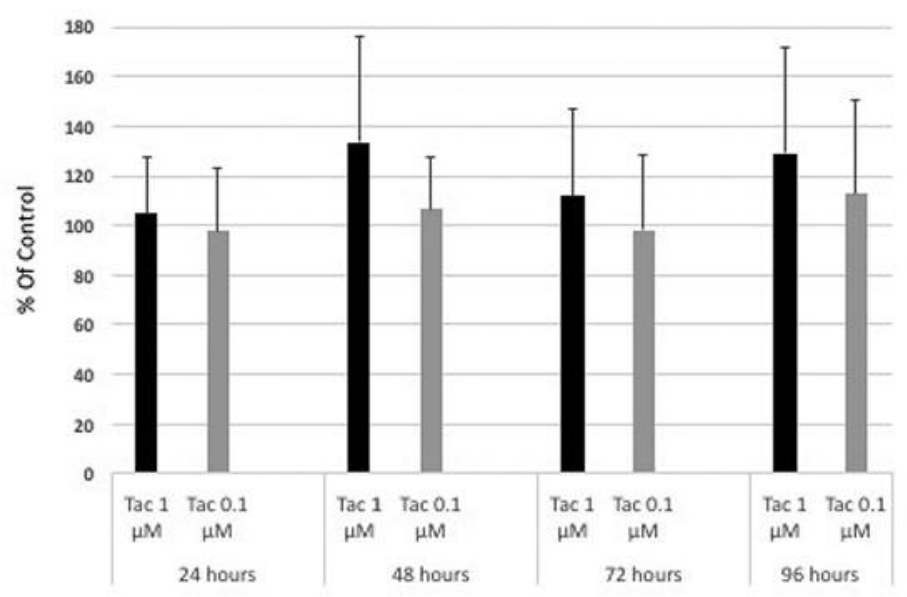

Figure 2. Influence of $10 \mu M(A)$ and $1 \mu M(B)$ mycophenolate mofetil (MMF) alone and in combination with tacrolimus (Tac) at different concentrations on the growth of HT-29 cells; tacrolimus alone did not influence proliferation of HT-29 cells (C). Results are expressed as percentage of the control values at the respective time point. Significantly different in $A:$ at $* p<0.001, * * p<0.002, * * * p<0.005$ compared to control, and ${ }^{\dagger} p<0.01$ compared to MMF alone; in B: at ${ }^{*} p<0.02$ and ${ }^{*}{ }^{*} p<0.002$ compared to control; ${ }^{\dagger} p<0.02$ compared to MMF alone. 


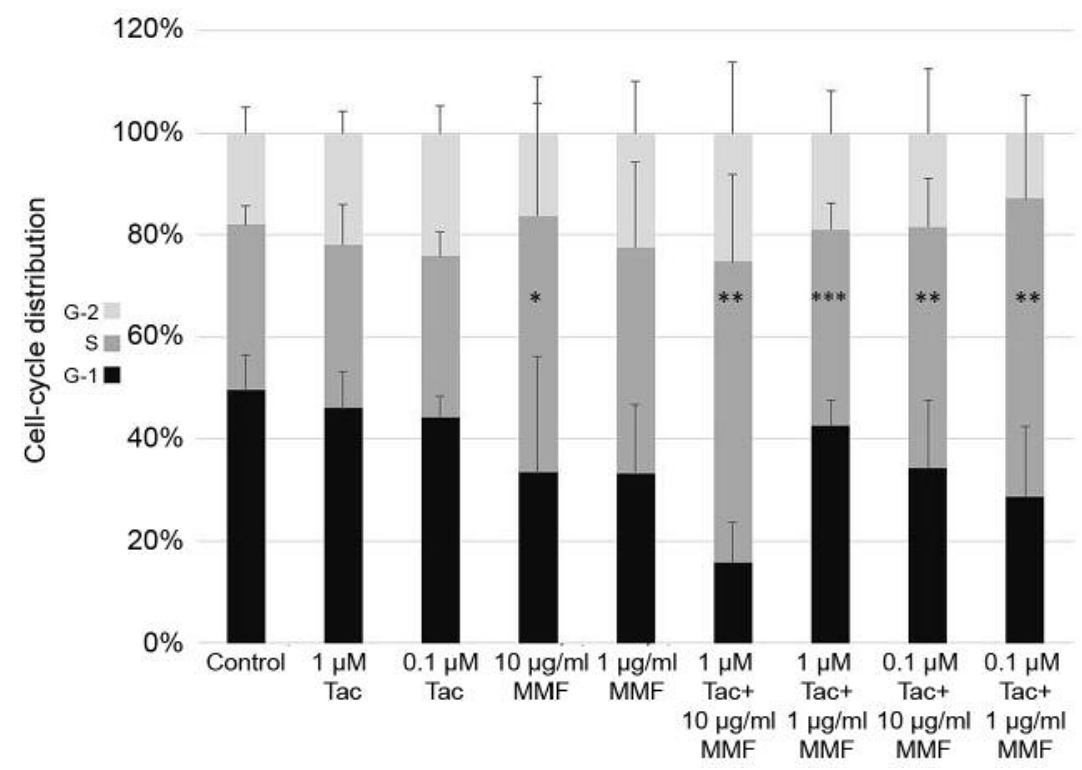

Figure 3. Mycophenolate mofetil (MMF) alone and in combination with tacrolimus (Tac) induced S-phase mitotic arrest of HL-29 cells after $48 \mathrm{~h}$ of treatment. Data are presented as mean of two independent experiments performed in quadruplicates. Significantly different of *p<0.04, **p<0.001 and $* * * p<0.03$ compared to control.

a potent immunosuppressive drug (9). Of note, MPA is completely metabolized in the liver, kidney and gastrointestinal tract by uridine disphosphate glucuronidase transferases (UDPGT) (13). It is noteworthy that in many tumors, the expression of IMPDH, particularly the isoform IMPDH2, is markedly up-regulated [reviewed in (14)].

To explore putative mechanisms involved in the anticancer action of MMF and tacrolimus on FAP adenomas, we selected the human colonic adenocarcinoma cell line HT29 for the following reasons. Firstly, these cancer cells, like FAP cells, harbor a nonsense APC gene mutation (5). Moreover, the HT29 cell line possesses the glucuronidation system capable of inactivating MPA (15), and, thereby, represents a versatile in vitro microsystem for assessing the biological effect of MMF or tacrolimus alone and in combination. Notably, an early work used the HT-29 cell line in vitro to study the metabolism of analogs of MPA (16).

In the present report, we demonstrated a dose-dependent antiproliferative effect of MMF alone and a synergistic antiproliferative effect of the combination of tacrolimus and MMF on human colonic adenocarcinoma cell line HT-29. The analysis of the cell cycle of HT-29 cells following $48 \mathrm{~h}$ of treatment with 1 or $10 \mu \mathrm{g} / \mathrm{ml} \mathrm{MMF}$ alone or in combination with tacrolimus demonstrated cell-cycle arrest in the S-phase, a cell-cycle stage associated with stalling of DNA replication.

A tenable possibility is that the restraining action of MMF and of its combination with tacrolimus on the human colonic adenocarcinoma cell line HT-29 and on FAP colonic crypt proliferation derives from the poor supply of purine nucleotides as a consequence of MMF-induced inhibition of IMPDH activity (14). One may suggest that that salvage of guanine via the salvage pathway is probably inadequate to satisfy the demanding needs of the rapidly dividing cancer cells. The depletion of guanine nucleotides is believed to underpin the action of IMPDH inhibitors; of note, guanine nucleotides serve as precursors for RNA and DNA and are involved in a vast array of biological events.

Current evidence attributes the anti-neoplastic effects of MMF to its ability to inhibit angiogenesis (17) and cell migration (18), and induce caspase-dependent apoptosis through both the intrinsic mitochondrial and extrinsic cytosolic pathways of apoptosis as a consequence of its interference with DNA synthesis. Of note, induction of apoptosis by IMPDH inhibitors has frequently been reported $(19,20)$. Although the analysis of kinetics of apoptosis in HT-29 cells following MMF and tacrolimus treatment was beyond the scope of this study, we noted expansion of a hypoploid sub-G $\mathrm{G}_{1}$ cell population (data not shown), concomitant with the observed S-phase arrest in the HT-29 cells following MMF and tacrolimus treatment, suggesting an enhanced rate of apoptosis.

A consistent finding in our study was the failure of tacrolimus on its own to interfere with the growth of the cancer cells and its ability to potentiate the anticancer action of MMF. It is pertinent at this point to mention that although the inhibitory effect of MMF on proliferation of colorectal 
cell cancer cell lines was noted three decades ago (21), the enthusiasm for using this drug for treatment of colorectal cancer has somewhat abated following the discovery of a mechanism of intrinsic resistance of intestinal cancer cell lines due to inactivation of MPA by glucuronidation (15). In this context, and of relevance to our study, Zucker et al. (22) observed increased bioavailability of MMF, as judged by the elevation of plasma concentration of MPA, in renal transplant patients treated with MMF in combination with tacrolimus and attributed it to the ability of tacrolimus to inhibit glucuronidation of MPA with a corresponding decrease of MPAG, the inactive glucuronide metabolite of MPA. Interestingly, this tacrolimus-mediated inhibitory effect on MPA degradation was shown in vitro to be exerted via the inhibition of UDPGT (23).

On the basis of these observations, it may be suggested that the contribution of tacrolimus to restraining the growth of colonic cancer cells, when used in combination with MMF, is related to the inhibition of intracellular MPA degradation, thus providing a sustained anti-growth effect of MPA. There is not, however, firm consensus as to whether tacrolimus is indeed involved in limiting MPA degradation, and until this is firmly proven, our mechanistic explanation, although attractive in its simplicity, remains to be validated.

Of interest is the observed discrepancy between the consistent cytopathic effect of MMF in combination with tacrolimus at 48, 72 and $96 \mathrm{~h}$, and the apparent normal cell-cycle distribution in all tested cell groups at $96 \mathrm{~h}$. It is worth noting that Chen et al. recently demonstrated the presence of fast- and slow-cycling cell subpopulations in tumors, including colonic tumors, with differential sensitivities to IMPDH inhibition by MPA (24). Whether the differential response of HT29 cells to prolonged exposure to the drugs observed in our study represents druginduced selection of HT-29 subpopulations with a different phenotypic background determining the responsiveness to MPA remains to be investigated.

Herein we presented the result of a small pilot study aimed at understanding the intriguing clinical case of complete reversion of colonic pre-neoplastic syndrome following treatment with combination of two immunosuppressive drugs. To the best of our knowledge, this study and our previous publication (4) represent the first direct evidence of an in vivo anti-growth effect of tacrolimus and MMF treatment of hereditary colon cancer. Further studies, aimed at shedding light on the molecular events underlying the observed phenomena, that include analysis of transcriptosomic changes induced by MMF and tacrolimus in our experimental setting, and the use of mouse models of colon cancer, are underway.

\section{Acknowledgements}

The work of Dr. G. Shubinsky is supported, in part, by the Israel Ministry of Immigrant Absorption.

\section{Conflicts of Interest}

None.

\section{References}

1 Farrugia D, Mahboob S, Cheshire J, Beqai I, Khosla S, Ray D and Sharif A: Malignancy-related mortality following kidney transplantation is common. Kidney Int 85: 1395-1403, 2014.

2 Kasiske B, Snyder J, Gilbertson D and Wang C: Cancer after kidney transplantation in the United States. Am J Transplant 4: 905-913, 2006.

3 Safaeian M, Robbins H, Berndt S, Lynch CF, Fraumeni JF and Engels EA: Risk of colorectal cancer after solid organ transplantation in the United States. Am J Trasplant 16: 960-967, 2016.

4 Pinsk V, Pinsk I, Ling G, Yerushalmi B, Osyntsov L and Ling E: Complete reversion of familial adenomatous polyposis coli phenotype associated with tacrolimus and mycophenolate mofetil treatment following kidney transplantation. Anticancer Res 37: 3105-3109, 2017.

5 Morin P, Vogelstein B and Kinzler K: Apoptosis and APC in colorectal tumorigenesis. Proc Natl Acad Sci USA 93: 7950-7954, 1996.

6 Hekhmate M, Ben-Shaul $\mathrm{Y}$ and Polak-Charcon S: A morphological study of a human adenocarcinoma cell line (HT29) differentiating in culture. Similarities to intestinal embryonic development. Cell Dif Dev 31: 207-218, 1995.

7 Nowak M, Tardivel S, Nguyen-Khoa T and Abreu S, Allaoui F, Fournier N, Chaminade P, Paul JL and Lacour B: Mycophenolate mofetil and rapamycin induce apoptosis in the human monocytic U937 cell line through two different pathways. J Cell Biochem 9999: 1-8, 2017.

8 Saitoh A, Matsuse R, Sugi K, Nakagawa K, Uchida K, Maemura K, Kojima K, Hirata I and Katsu KI: Cyclosporine A inhibits interleukin- 8 production in a human colon epithelial cell line (HT-29). J Gastroenterol 32: 605-610, 1997.

9 Allison A and Eugui E: Mycophenolate mofetil and its mechanisms of action. Immunopharmacol 47: 85-118, 2000.

10 Koehl G, Wagner F, Stoeltzing O, Lang S, Steinbauer M, Schlitt $\mathrm{H}$ and Geissler E: Mycophenolate mofetil inhibits tumor growth and angiogenesis but variable antitumor effects in vivo, possibly related to bioavailability. Transplant 83: 607-614, 2007.

11 Kuypers D, Le Meur Y, Cantarovich M, Tredger M, Tett S, Cattaneo D, Tönshoff B, Holt D, Chapman J and van Gelder T: Consensus report on therapeutic drug monitoring of mycophenolic acid in solid organ transplantation. Clin J Am Soc Nephrol 5: 341-358, 2010.

12 Allegra C, Paik S, Colangelo L, Parr A, Kirsch I, Kim G, Klein P, Johnston P, Wolmark N and Wieand HS: Prognostic value of thymidylate synthase, Ki-67, and p53 in patients with Dukes' B and $\mathrm{C}$ colon cancer: A National Cancer Institute-National Surgical Adjuvant Breast and Bowel Project Collaborative Study. J Clin Oncol 21: 241-250, 2003.

13 Staatz $C$ and Tett SE: Clinical pharmacokinetics and pharmacodynamics of mychophenolate in solid organ transplant recipients. Clin Pharmacokinet 46: 13-58, 2007.

14 Shu Q and Nair V: Inosine monophosphate dehydrogenase (IMPDH) as a target in drug discovery. Med Res Rev 28: 219232, 2008. 
15 Franklin T, Jacobs V, Jones G, Plé P and Bruneau P: Glucuronidation associated with intrinsic resistance to mycophenolic acid in human colorectal carcinoma cells. Cancer Res 56: 984-987, 1996.

16 Franklin T, Jacobs V, Jones G and Ple P: Human colorectal carcinoma cells in vitro as a means to assess the metabolism of analogs of mycophenolic acid. Drug Metab Dispos 25: 367-370, 1997.

17 Chong C, Qian D, Pan F, Wei Y, Pili R, Sullivan DJ and Liu JO: Identification of type 1 inosine monophosphate dehydrogenase as an antiangiogenic drug target. J Med Chem 49: 2677-2680, 2006.

18 Engl T, Makarević J, Relja B, Natsheh I, Müller I, Beecken WD, Jonas D and Blaheta R: Mycophenolate mofetil modulates adhesion receptors of the beta I integrin family on tumor cells: Impact on tumor recurrence and malignancy. BMC Cancer 5: 4, 2005.

19 Végsö G, Sebestyén A, Paku S, Barna G, Hajdu M, Tóth M, Járay J and Kopper L: Antiproliferative and apoptotic effects of mycophenolic acid in human B-cell non-Hodgkin lymphomas. Leukemia Res 31: 1003-1008, 2007.

20 Takebe N, Cheng X, Fandy T, Srivastava R, Wu S, Shankar S, Bauer K, Shaughnessy J and Tricot G: IMP dehydrogenase inhibitor mycophenolate mofetil induces caspase-dependent apoptosis and cell cycle inhibition in multiple myeloma cells Mol Cancer Ther 5: 457-466, 2006.
21 Tressler R, Garvin L and Slate D: Anti-tumor activity of mycophenolate mofetil against human and mouse tumors in vivo. Int J Cancer 57: 568-573, 1994.

22 Zucker K, Rosen A, Tsaroucha A, de Faria L, Roth D, Ciancio G, Esquenazi V, Burke G, Tzakis A and Miller J: Unexpected augmentation of mycophenolic acid pharmacokinetics in renal transplant patients receiving tacrolimus and mycophenolate mofetil in combination therapy, and analogous in vitro findings. Transpl Immunol 5: 225-232, 1997.

23 Zucker K, Tsaroucha A, Olson L, Esquenazi V, Tzakis A and Miller J: Evidence that tacrolimus augments the bioavailability of mycophenolate mofetil through the inhibition of mycophenolic acid glucuronidation. Ther Drug Monit 21: 35-43, 1999.

24 Chen K, Cao W, Li J, Sprengens D, Hernanda P, Kong X, van der Laan L, Man K, Kwekkeboom J, Metselaar H, Peppelenbosch M and Pan Q: Differential sensitivities of fast- and slow-cycling cancer cells to inosine monophosphate dehydrogenase 2 inhibition by mycophenolic acid. Mol Med 21: 792-802, 2015.

Received April 4, 2018

Revised May 6, 2018

Accepted May 9, 2018 